\title{
Identificação de Anopheles (Kerteszia) cruzii Dyar \& Knab e Anopheles (Kerteszia) homunculus Komp (Diptera, Culicidae, Anophelinae) através de marcadores moleculares (RAPD e RFLP) ${ }^{1}$
}

\author{
Daniéla C. Calado ${ }^{2} \&$ Mario A. Navarro-Silva ${ }^{2}$ \\ ${ }^{1}$ Contribuição número 1584 do Departamento de Zoologia, Universidade Federal do Paraná. \\ 2 Laboratório de Entomologia Médica e Veterinária, Departamento de Zoologia, Universidade Federal do Paraná. Caixa \\ Postal 19020,81531-980 Curitiba, Paraná, Brasil.E-mail: danielacalado@hotmail.com, mnavarro@ufpr.br
}

\begin{abstract}
Identification of Anopheles (Kerteszia) cruzii Dyar \& Knab and Anopheles (Kerteszia) homunculus Komp (Diptera, Culicidae, Anophelinae) by molecular markers (RAPD and RFLP). Adults females, larvae and pupae of A. cruzii Dyar \& Knab, 1908 and A. homunculus Komp, 1937 are very similar morphologically, causing difficulty in their proper identification with traditional taxonomic characters. Here, RAPD and RFLP were used to resolve this problem of identification of these two species. Mosquito DNA, amplified with the random primers OPY-05 and OPY-10, and enzymatic digestion of the ITS2 region with HaellI and Sau96I generated species-specific patterns. Thus, through the use of these molecular markers, these two species may be correctly identified when only females, larvae ou pupae are collected, or when individuals are damaged in the collection process.

KEYWORDS. Anopheles (Kerteszia), identification, malaria vector, random amplified polymorphic DNA, second internal transcribed spacer.
\end{abstract}

RESUMO. Fêmeas adultas, larvas e pupas de A. cruzii Dyar \& Knab, 1908 e A. homunculus Komp, 1937 são muito semelhantes morfologicamente, sendo difícil a identificação através dos caracteres taxonômicos tradicionais. Nesse estudo, RAPD e RFLP foram utilizados para facilitar a identificação dessas espécies. O DNA amplificado com os iniciadores OPY-05 e OPY-10, e a digestão da região ITS2 com as enzimas HaellI e Sau96I geraram padrões espécieespecíficos. Desta forma, através do uso desses marcadores moleculares, as duas espécies podem ser corretamente identificadas quando somente fêmeas, larvas ou pupas são coletadas, ou quando os indivíduos são danificados durante a coleta.

PALAVRAS CHAVE. Anopheles (Kerteszia), DNA polimórfico amplificado ao acaso, identificação, segundo espaçador interno transcrito, vetor.

O gênero Anopheles Meigen, 1818, compreende aproximadamente 400 espécies, distribuídas em quatro subgêneros: Anopheles Meigen, 1818, Kerteszia Theobald, 1905, Nyssorhynchus Blanchard, 1902 e Cellia Theobald, 1902 (SALLum et al. 2000). No Brasil, as espécies de Nyssorhynchus são responsáveis, principalmente, pela manutenção da malária na região Amazônica, enquanto Kerteszia destaca-se pela transmissão de Plasmodium Marchiafava \& Celli, 1885 em áreas recobertas pela Floresta Atlântica. Dentre as espécies do subgênero Kerteszia, Anopheles (K.) cruzii Dyar \& Knab, 1908, Anopheles (K.) homunculus Komp, 1937 e Anopheles (K.) bellator Dyar \& Knab, 1906 são considerados vetores potenciais de Plasmodium nas regiões sul e sudeste do Brasil.

Muitos registros quanto à ocorrência de Anopheles (K.) cruzii são duvidosos e possivelmente estão relacionados a outras espécies do subgênero Kerteszia. ZavorTinK (1973) apontou uma vasta área de distribuição, que inclui a Venezuela, Peru, Panamá,
Guianas, Equador, Costa Rica, Colômbia, Brasil, Bolívia e Argentina. Entretanto, WiLKerson \& Peyton (1991) e Forattini (1962) restringiram essa distribuição ao território brasileiro, abrangendo os estados de Pernambuco, Sergipe, Bahia, Espírito Santo, Rio de Janeiro, São Paulo, Paraná, Santa Catarina e Rio Grande do Sul.

Anopheles (K.) homunculus apresenta distribuição descontínua, ocorrendo em Trinidad e Tobago, Bolívia (Cochabamba), Venezuela (Bolivar, Monaguas, Tachira, Trujillo), Colômbia (Meta) e Brasil (São Paulo, Paraná, Santa Catarina). Não existem evidências concretas sobre a ampla área de distribuição intermediária às localidades onde já foi encontrada (ForATTINI 2002), e por isso não há garantias de que todos os registros referem-se a uma mesma espécie.

As fêmeas de Anopheles (K.) cruzii são morfologicamente semelhantes às de Anopheles (K.) homunculus (Forattini 1962, Martins 1958, Zavortink 1973, Wilkerson \& Peyton 1991), po- 
dendo constituir um complexo de espécies (Rosa-Freitas et al. 1998). Segundo Wilkerson \& Peyton (1991) as fêmeas de Anopheles (K.) cruzii diferenciam-se de Anopheles (K.) homunculus pelos caracteres presentes nos palpos maxilares. Entretanto, esses caracteres são de difícil interpretação e, portanto, a identificação específica segura somente é alcançada através da análise da genitália masculina. Além de considerar os caracteres presentes nos palpos maxilares como diagnósticos, Martins (1958) apontou ainda que as fêmeas de Anopheles (K.) cruzii apresentam tegumento abdominal de coloração vermelha uniforme ou vermelha com áreas claras; enquanto Anopheles (K.) homunculus possui tegumento com manchas escuras e claras, mas nunca avermelhadas.

As larvas de Anopheles (K.) cruzii e Anopheles (K.) homunculus também são muito semelhantes morfologicamente, mas segundo Lima (1952) essas podem ser diferenciadas pela coloração do tegumento e grau de quitinização do segmento anal. Em Anopheles (K.) cruzii, o segmento anal é pouco quitinizado e o tegumento apresenta coloração amarelada ou avermelhada. Enquanto, as larvas de Anopheles (K.) homunculus apresentam segmento anal muito quitinizado e tegumento de coloração escura.

Apesar da existência de caracteres diagnósticos para Anopheles (K.) cruzii e Anopheles (K.) homunculus, a identificação específica através da morfologia externa é algumas vezes prejudicada pelo alto grau de variabilidade observada nos caracteres morfológicos diferenciais (ForATTINI 1962) e pela perda ou dano de diferentes partes do corpo do inseto durante o processo de captura. Este problema pode ser contornado através da utilização de outros caracteres, por exemplo moleculares, os quais podem constituir importante ferramenta para identificação de espécies vetoras.

Tendo em vista a importância epidemiológica, similaridade morfológica e a ocorrência simpátrica nos estados de São Paulo, Paraná e Santa Catarina, este estudo teve como objetivo: analisar a possibilidade de identificação de Anopheles (K.) cruzii e Anopheles (K.) homunculus, através das técnicas PCRRAPD e PCR-RFLP.

\section{MATERIAL E MÉTODOS}

\section{Amostras analisadas}

As capturas de Anopheles (K.) cruzii foram realizadas nas localidades de Morretes (Estação Experimental do IAPAR, $48^{\circ} 49^{\prime} \mathrm{W}, 2^{\circ} 30^{\prime} \mathrm{S}$ ), Guaratuba (propriedade particular), Paranaguá (Parque Estadual do Palmito, $25^{\circ} 35^{\prime} \mathrm{S}, 48^{\circ} 32^{\prime} \mathrm{W}$; e Ilha do Mel, 25³0'36.0”S, 48¹8'44.7”W) (Paraná), São Francisco do Sul (propriedade particular, área de preservação permanente, $26^{\circ} 14^{\prime} 03.4^{\prime \prime} \mathrm{S}, 48^{\circ} 41^{\prime} 09.3^{\prime \prime} \mathrm{W}$ ) e Florianópolis (Unidade de Conservação Ambiental Desterro, Universidade Federal de Santa Catarina, 27 $31^{\prime} 50.8^{\prime \prime} \mathrm{S}, 48^{\circ} 30^{\prime} 44.3^{\prime \prime} \mathrm{W}$ ) (Santa Catarina) e Cananéia $\left(24^{\circ} 53^{\prime} 26.5^{\prime \prime}\right.$ S, 47050'16.5”W). (São Paulo). Anopheles (K.) homunculus foi coletada em São Francisco do Sul.

As fêmeas capturadas foram individualizadas para obten- ção da geração F1 e posterior identificação. Parte dos indivíduos obtidos em laboratório foi utilizada para obtenção de exúvias larval e pupal, e exemplares adultos, os quais foram devidamente montados e depositados na Coleção Entomológica Pe. Jesus Santiago Moure (DZUP) do Departamento de Zoologia da Universidade Federal do Paraná. O restante do material foi mantido até a obtenção de adultos, os quais foram sacrificados por congelamento e armazenados em etanol absoluto a $-20^{\circ} \mathrm{C}$, para serem utilizados nas análises moleculares. Para efeito de comparação, exemplares de Anopheles (K.) bellator Dyar \& Knab, 1906 (Cananéia e Paranaguá), embora morfologicamente distintos das demais espécies, também foram analisados. Cento e noventa e duas amostras foram analisadas.

\section{Extração de DNA e condições da PCR-RAPD}

A extração de DNA foi realizada segundo protocolo de Cheung et al. (1993) modificado por Carvalho \& Vieira (2001), utilizando um exemplar adulto. A reação de amplificação foi conduzida em volume total de $25 \mu \mathrm{l}$, contendo 15-30 ng de DNA, 1X PCR buffer, $3 \mathrm{mM}$ de $\mathrm{MgCl}_{2}, 100 \mu \mathrm{M}$ de cada dNTP, 5 pmol de iniciador (Operon Technologies Inc. Alameda, CA.), 1 U de Taq DNA polimerase (Invitrogen) e água Milli-Q estéril para completar o volume final. A PCR foi realizada em termociclador PTC-100 ${ }^{\mathrm{TM}}$ (MJ Research, Inc. Watertown, MA), utilizando-se os seguintes ciclos de temperatura: desnaturação inicial a $94^{\circ} \mathrm{C}$ por três minutos, 41 ciclos de desnaturação a $94^{\circ} \mathrm{C}$ por um minuto, anelamento a $35^{\circ} \mathrm{C}$ por um minuto e extensão a $72^{\circ} \mathrm{C}$ por dois minutos, e extensão final a $72^{\circ} \mathrm{C}$ por quatro minutos. Cada reação foi repetida uma a duas vezes para confirmação da posição e reprodutibilidade das bandas. Controles negativos foram incluídos.

Sete iniciadores foram utilizados para a comparação entre as três espécies, OPA-01 (5'-CAGGCCCTTC-3'), OPA-11 (5'CAATCGCCGT-3'), OPY-02 (5'-CATCGCCGCA-3'), OPY-05 (5'GGCTGCGACA-3'), OPY-10 (5'-CAAACGTGGG-3'), OPY-15 (5'AGTCGCCCTT-3') e OPY-16 (5'-GGGCCAATGT-3').

Os produtos de PCR foram fracionados em gel de agarose $1,5 \%$ contendo $0,5 \mathrm{X} \mathrm{TBE}$, a $5 \mathrm{~V} / \mathrm{cm}$ durante três horas e corados com solução de brometo de etídio $(0,5-1 \mu \mathrm{g} / \mathrm{ml})$ por $20-30$ minutos. Como marcador de peso molecular foi utilizado $100 \mathrm{pb}$ DNA Ladder (Invitrogen). O cálculo do peso molecular aproximado das bandas foi realizado com auxílio do sistema KODAK Digital Science EDAS 120.

\section{Análise dos resultados (PCR-RAPD)}

Exemplares de Anopheles (K.) cruzii, Anopheles (K.) bellator e Anopheles (K.) homunculus foram avaliados de forma conjunta utilizando o método UPGMA e a distância de NeI (1972), com auxílio do programa POPGENE. Para evitar problemas quanto à homologia das bandas a serem comparadas, foram utilizadas somente aquelas mais freqüentes entre amostras de cada espécie. Também foram analisadas as bandas compartilhadas por duas ou mais espécies, e que se apresentaram consistentes. 


\section{PCR-ITS2}

Cada reação foi conduzida em volume total de $25 \mu \mathrm{l}, 1 \mathrm{X}$ tampão, $3 \mathrm{mM}$ de $\mathrm{MgCl}_{2}, 200 \mu \mathrm{M}$ de cada dNTP, 15 pmol de cada iniciador (Invitrogen), 4-6ng/ $\mu$ l de DNA, 1 U de Taq DNA polimerase (Invitrogen) e água Milli-Q estéril para completar o volume final. Os iniciadores CP17 (5'-GCGCCGCGGTGTGAAC TGCAGGACACATG-3') e CP16 (5'-GCGGGTACCATGCTTAAA TTTAGGGGGTA-3') (Mallafronte et al. 1997) foram utilizados na reação de amplificação. A reação de amplificação foi realizada utilizando-se os seguintes ciclos de temperatura: desnaturação inicial a $94^{\circ} \mathrm{C}$ por cinco minutos, 40 ciclos de desnaturação a $94^{\circ} \mathrm{C}$ por dois minutos, anelamento a $58^{\circ} \mathrm{C}$ por dois minutos e extensão a $72^{\circ} \mathrm{C}$ por dois minutos; seguidos de extensão final a $72^{\circ} \mathrm{C}$ por cinco minutos. A amplificação da região ITS2 foi realizada em 48 amostras, selecionadas a partir dos resultados obtidos através da PCR-RAPD.

\section{Reação de restrição}

Seis enzimas foram utilizadas para restrição da região ITS2, as quais reconhecem seqüências de $4 \mathrm{pb}$ (BstUI, HaeIII e TaqI), $5 \mathrm{pb}$ (Sau96I e HinfI) e 6pb (HincII). O sistema contendo $5-10 \mathrm{ml}$ do produto de amplificação, excesso de enzima (3-5U), 1X tampão e água Milli-Q para volume final de 10-20ml, foi incubado durante 3-4 horas sob temperatura adequada à cada endonuclease. Após a reação de restrição, os fragmentos obtidos foram fracionados em gel de agarose $2 \%$ a $4 \mathrm{~V} / \mathrm{cm}$, corados com solução de brometo de etídio e fotografados sob luz ultravioleta. Como marcadores de peso molecular foram utilizados: $1 \mathrm{~Kb}$ Plus DNA Ladder (Invitrogen) e 50pb DNA Ladder (Invitrogen).

\section{RESULTADOS E DISCUSSÃO}

\section{PCR-RAPD}

A maioria dos iniciadores utilizados amplificou perfis distintos para Anopheles (K.) cruzii, Anopheles (K.) homunculus e Anopheles (K.) bellator, permitindo a pronta identificação dessas espécies (Figs 1 e 2). Embora, Anopheles (K.) bellator possa ser diferenciada das demais através de caracteres morfológicos, sua utilização no presente estudo justifica-se pela presença de fragmentos com pesos moleculares próximos aos obtidos para as outras espécies e que, portanto, poderiam ser erroneamente utilizados como marcadores espécie-específicos.

Os iniciadores OPA-11, OPY-16, OPY-15 e OPA-01 forneceram fragmentos muito variáveis em Anopheles (K.) cruzii, dificultando a identificação quando um grande número de amostras é analisado, não sendo possível a obtenção de fragmentos fixados em todas as amostras da espécie. O iniciador OPY-02 amplificou perfis muito semelhantes para Anopheles (K.) cruzii e Anopheles (K.) homunculus, sendo difícil a separação dessas espécies. Já os iniciadores OPY-05 e OPY-10, forneceram padrões eletroforéticos claramente distintos para as duas espécies e podem ser utilizados para obtenção de caracteres taxonômicos.

Para verificar a relação de similaridade entre as três espécies, quarenta bandas foram selecionadas. A análise de agrupa-
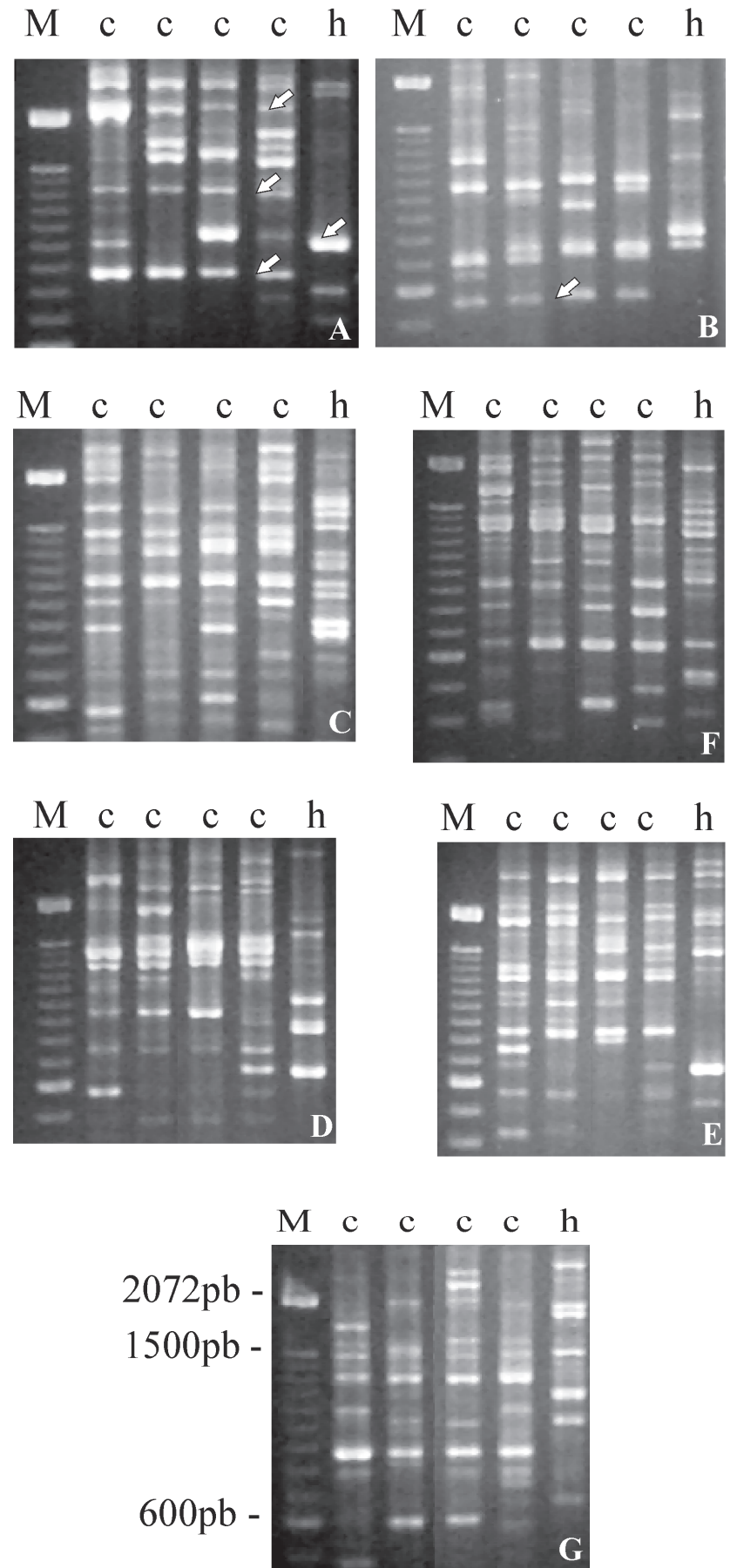

Figura 1. Comparação entre os fragmentos amplificados através de PCR-RAPD para indivíduos de Anopheles cruzii (c) e Anopheles homunculus (h), obtidos com os iniciadores: (A) OPY-05; (B) OPY10; (C) OPY-02; (D) OPA-11; (E) OPY-15; (F) OPY-16 e (G) OPA-01. (M) Marcador 100pb DNA Ladder (Invitrogen). Seta indicam marcadores (somente em iniciadores passíveis de serem utilizados para identificação específica - ver texto).

Revista Brasileira de Zoologia 22 (4): 1127-1133, dezembro 2005 

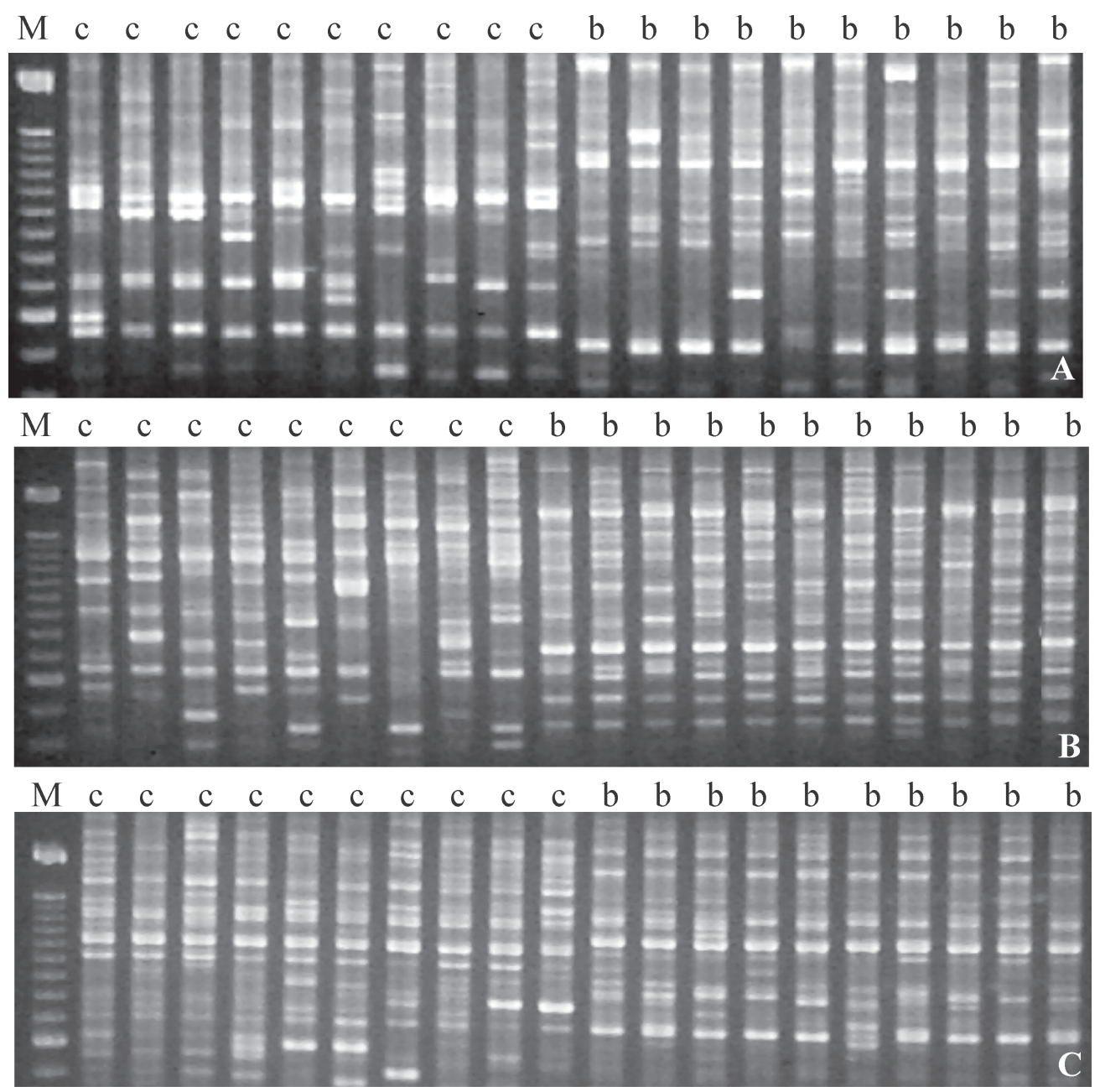

Figura 2. Comparação entre os fragmentos amplificados através de PCR-RAPD para indivíduos de Anopheles cruzii (c) e Anopheles belllator (b), obtidos com os iniciadores: (A) OPY-10; (B) OPY-16 e (C) OPY-02.

mento através do método UPGMA e distância de NeI (1972) mostrou que as diferentes espécies podem ser caracterizadas através da utilização de fragmentos amplificados pela PCRRAPD. As amostras de Anopheles (K.) bellator apresentaram-se mais distintas daquelas pertencentes a Anopheles (K.) homunculus e Anopheles (K.) cruzii, corroborando as diferenças observadas na morfologia externa. O dendrograma gerado a partir dessa análise está representado na figura 3.

Tendo em vista, possíveis problemas quanto a reprodutibilidade da técnica em outros laboratório e a utilização de diferentes reagentes, os iniciadores OPY-10 e OPY-05 podem ser empregados com maior sucesso na identificação de Anopheles (K.) cruzii e Anopheles (K.) homunculus, pois geram perfis diferentes para as duas espécies, com ausência de bandas compartilhadas. A presença de fragmentos monomórficos em determinada espécie e sua ausência em espécies relacionadas, pode ser utilizada como caráter taxonômico. WILKERSON et al. (1995a, b), por exemplo, identificaram quatro espécies do complexo Anopheles (N.) albitarsis através de marcadores RAPD e consideram a técnica efetiva para a identificação de espécies que constituem complexos. A capacidade da técnica em gerar padrões de bandas espécie-específicos, pode ser utilizada para a identificação de grupos onde os caracteres morfológicos presentes nos estágios adulto e imaturo não permitem diagnóstico (BLACK et al. 1992). Devido ao grande número de fragmentos amplificados e ao elevado número de iniciadores disponíveis para o uso, a PCR-RAPD fornece um arsenal de marcadores que podem ser utilizados na identificação específica (RAICH et al., 1993).

\section{PCR-RFLP}

A amplificação da região ITS2 e parte dos genes $5.8 \mathrm{~S}$ e $28 \mathrm{~S}$ de Anopheles (K.) cruzii resultou em fragmento de aproximadamente $490 \mathrm{pb}$ (incluindo os dois iniciadores) que diferen-

Revista Brasileira de Zoologia 22 (4): 1127-1133, dezembro 2005 


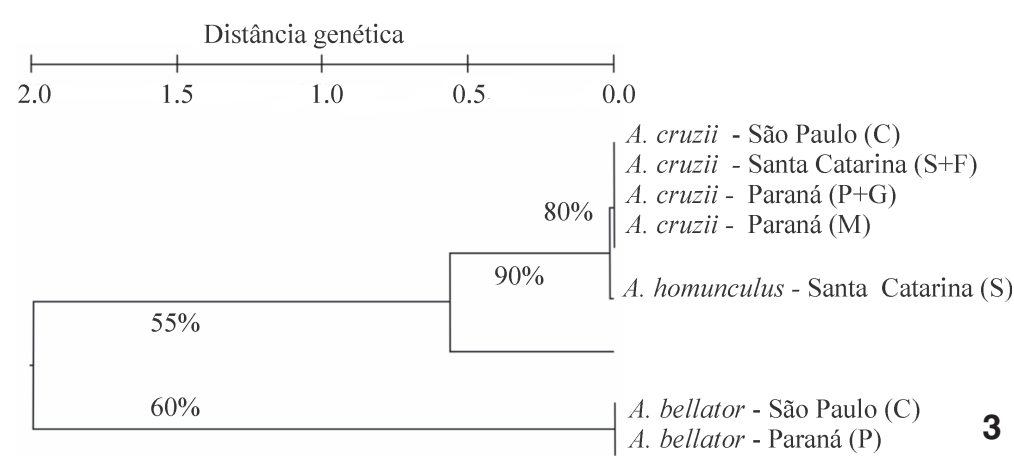

Figuras 3-4. (3) Dendrograma construído a partir de bandas obtidas através da técnica PCR-RAPD para Anopheles cruzii, Anopheles bellator e Anopheles homunculus. Agrupamento através do método UPGMA e distância de Nel (1972). (C) Cananéia, (S) São Francisco do Sul, (F) Florianópolis, (P) Paranaguá, (G) Guaratuba, (M) Morretes; (4) produto de amplificação da região ITS2 e parte dos genes 5.8S e 285 de Anopheles bellator (1), Anopheles cruzii (2) e Anopheles homunculus (3). (M) Marcador 50pb DNA Ladder (Invitrogen).
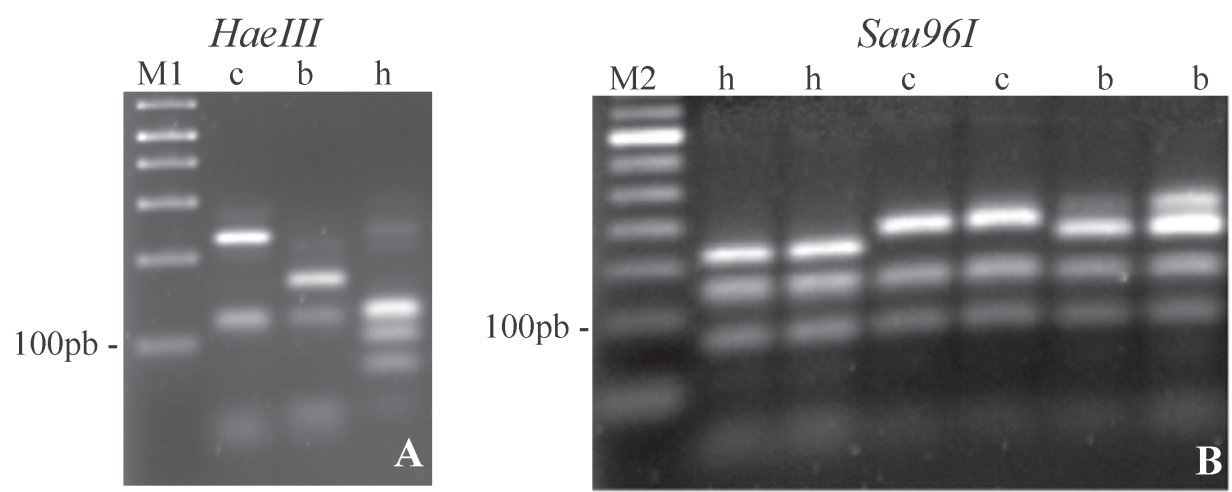

Figura 5. Padrão de restrição da região ITS2 e parte dos genes 5.8S e $28 \mathrm{~S}$ de Anopheles cruzii (c), Anopheles bellator (b) e Anopheles homunculus (b) com HaellI (A) e Sau96I (B). M1 Marcador 1Kb Plus DNA Ladder (Invitrogen) e M2 Marcador 50 pb DNA Ladder (Invitrogen).

cia-se discretamente daqueles obtidos para Anopheles (K.) homunculus e Anopheles (K.) bellator (Fig. 4). A similaridade quanto ao peso molecular dos produtos amplificados para Anopheles (K.) cruzii e Anopheles (K.) homunculus, não permite que essas sejam identificadas apenas pelo tamanho da região ITS2, sendo necessária a restrição dessa região para o diagnóstico efetivo.

Com exceção de HincII, as endonucleases utilizadas apresentaram sítios de restrição na região ITS2 das três espécies. Em Anopheles (K.) bellator, não foi verificado sítio de restrição para HincII, sendo observada apenas uma banda, cujo peso molecular corresponde ao fragmento intacto.

A maioria das enzimas utilizadas não permitiu a identificação de Anopheles (K.) cruzii e Anopheles (K.) homunculus, indicando certa homologia entre a região ITS2 dessas espécies. As endonucleases, BstUI, TaqI, HinfI e HincII, forneceram padrões de restrição muito semelhantes para Anopheles (K.) cruzii e Anopheles (K.) homunculus, dificultando o diagnóstico específico devido a baixa resolução obtida em gel de agarose $2 \%$. Porém, a restrição do ITS2 com Sau96I e HaeIII produziu perfis de clivagem espécie-específicos, que permitiram a pronta identifi- cação dos mosquitos analisados (Fig. 5). Isto ocorreu, possivelmente, porque a região ITS2 é rica em GC e as enzimas Sau96I e HaeIII reconhecem as seqüências $g / g n c c$ e $g g / c c$, respectivamente, havendo nesse caso maior probabilidade de detectar diferenças.

A clivagem do ITS2 de Anopheles (K.) cruzii com HaeIII gerou três bandas visíveis em gel de agarose com pesos moleculares aproximados de 230pb, 130pb e 40pb. A comparação entre os perfis obtidos e as seqüências disponíveis no GenBank (AF027165 e AF035227) para essa espécie, indicam que outros fragmentos foram gerados, porém a baixa resolução em agarose e a co-migração de diferentes fragmentos, não permitem a visualização das demais bandas. Em Anopheles (K.) homunculus, o número de bandas visíveis foi semelhante ao obtido para Anopheles (K.) cruzii, porém o peso molecular dos fragmentos de restrição é claramente distinto e permitem a pronta separação dessas espécies. O mesmo foi observado para os perfis obtidos com Sau96I. A partir desses resultados verificou-se que a restrição da região ITS2 de Anopheles (K.) cruzii e Anopheles (K.) homunculus com Sau96I e HaeIII, pode ser utiliza-

Revista Brasileira de Zoologia 22 (4): 1127-1133, dezembro 2005 
da para diagnóstico específico. E apesar da similaridade morfológica, as duas espécies apresentam diferenças na região ITS2 que podem ser utilizadas como caracteres taxonômicos moleculares.

Em Anopheles (K.) bellator, diferenças foram observadas quanto aos padrões gerados após restrição do ITS2 com a enzima Sau96I, cuja soma dos fragmentos gerados ultrapassa o peso molecular do fragmento intacto, o que sugere duas possibilidades: falha da reação de clivagem devido a presença de algum agente inibidor ou presença de mais de uma cópia da região ITS2. A primeira possibilidade foi descartada após realização de nova PCR seguida de restrição, as quais geraram os mesmos resultados. Além disso, o restante do produto de PCR foi clivado com outra enzima e gerou fragmentos cuja soma foi compatível com a observada para o fragmento não clivado. Porém, a confirmação da existência de heterogeneidade intragenômica em Anopheles (K.) bellator, deve ser confirmada através da clonagem e seqüenciamento de vários clones de um mesmo indivíduo. Embora a maioria das espécies de Anopheles apresente pouca ou nenhuma variabilidade intraespecífica e intraindividual (LinTon et al. 2002, PHuc et al. 2003), em algumas espécies é possível detectar polimorfismos intragenômicos na seqüência da região ITS2 (BeEBE et al. 2001, GAO et al. 2004).

Apesar da possibilidade de variação intragenômica em algumas espécies de Anopheles, a PCR-RFLP mostrou-se eficiente na separação de Anopheles (K.) cruzii e Anopheles (K.) homunculus. A dificuldade encontrada para identificação dessas espécies através de caracteres morfológicos, pode ser contornada com obtenção de outros caracteres taxonômicos gerados por metodologias alternativas, como por exemplo, PCRRAPD e PCR-RFLP. Caracteres moleculares podem constituir importante ferramenta para identificação específica, principalmente quando apenas fêmeas são coletadas e não é possível a obtenção de indivíduos machos em laboratório, ou quando os exemplares são danificados durante a coleta e por isso são difíceis de serem identificados morfologicamente.

\section{AGRADECIMENTOS}

Ao Instituto Ambiental do Paraná pela concessão de licença para coleta na Estação Ecológica da Ilha do Mel; ao pesquisador Dr. Luiz Gonzaga Esteves Vieira do Laboratório de Biotecnologia Vegetal do Instituto Agronômico do Paraná pelo apoio técnico e cessão do laboratório para realização das análises com marcadores moleculares, e ao CNPq pelas bolsas de Doutorado (D.C.C. - Processo: 140698/2001-9) e de produtividade em pesquisa (M.A.N.S. - Processo: 302350/2003-9).

\section{REFERÊNCIAS BIBLIOGRÁFICAS}

Beebe, N.W.; J. Maung; A.F. Van den Hurk; J.T. Ellis \& R.D. Cooper. 2001. Ribosomal DNA spacer genotypes of the Anopheles bancroftii group (Diptera: Culicidae) from Australia and Papua New Guinea. Insect Molecular Biology, Oxford, 10
(5): 407-413.

Black, W.C. IV; N.M. Duteau; G.J. Puterka; J.R. Nechols \& J.M. PetToRini. 1992. Use of random amplified polymorphic DNA polymerase chain reaction (RAPD-PCR) to detect DNA polymorphisms in aphids (Homoptera: Aphididae). Bulletin of Entomological Research, Wallingford, 82: 151-159.

Carvalho, A.O. \& L.G.E. Vieira. 2001. Determinação das condições ótimas para análise de PCR-RAPD em Atta sexdens rubropilosa Forel (Hymenoptera: Formicidae). Neotropical Entomology, Londrina, 30 (4): 593-600.

Cheung, W.Y.; N. Hubert \& B.S. LANDry. 1993. A simple and rapid DNA microextraction method for plant, animal and insect suitable for RAPD and other PCR analyses. PCR Methods and Applications, New York, 3: 69-70.

Forattini, O.P. 1962. Entomologia Médica. São Paulo, Editora da Faculdade de Higiene e Saúde Pública, vol. 1, 662p.

Forattini, O.P. 2002. Culicidologia Médica. São Paulo, Editora da Universidade de São Paulo, 860p.

Gao, Q.; N.W. Beebe \& R.D. Cooper. 2004. Molecular identification of the malaria vector Anopheles anthropophagus and Anopheles sinensis (Diptera: Culicidade) in Central China using polymerase chain reaction and appraisal of their position within the Hyrcanus group. Journal of Medical Entomology, Lanham, 41 (1): 5-11.

Lima, M.M. 1952. Do diagnóstico diferencial entre o Anopheles (Kerteszia) cruzii e o Anopheles (Kerteszia) homunculus na fase larvária. Revista Brasileira de Malariologia e Doenças Tropicais, Rio de Janeiro, 4: 401-411.

Linton, Y.N.; A. Samanidou-Voyadjoglou \& R.E. Harbach. 2002. Ribosomal ITS2 sequence data for Anopheles maculipennis and $A n$. messeae in northern Greece, with a critical assesment of previously published sequences. Insetc Molecular Biology, Oxford, 11 (4): 379-383.

Mallafronte, R.S.; M.T. Marrelli; G.C. Carreri-Bruno; P.R. Urbinatti \& O. MarinotTi. 1997. Polymorphism in the second internal spacer (ITS2) of Anopheles (Kerteszia) cruzii (Diptera: Culicidae) from the State of São Paulo, Brazil. Memórias do Instituto Oswaldo Cruz, Rio de Janeiro, 92 (Supl. I): 306.

Martins, C. M. 1958. Do diagnóstico diferencial específico entre o Anopheles (Kerteszia) cruzii cruzii e o Anopheles (Kerteszia) homunculus pelos caracteres dos adultos fêmeas (Diptera, Culicidae). Revista Brasileira de Malariologia e Doenças Tropicais, Rio de Janeiro, 10: 429-430.

NeI, M. 1972. Genetic distance between populations. American Naturalist, Chicago, 106: 283-292.

Phuc, H.K.; A.J. Ball; N.V. Hank; N.T. Tu; N.G. Lien; A. Verardi \& H. Townson. 2003. Multiplex PCR assay for malaria vector Anopheles minimus and four related species in the Myzomyia series from Southeast Asia. Medical and Veterinary Entomology, London, 17: 423-428.

Raich, T.J.; J.L. Archer; M.A. Robertson; W.J. TABachnik \& B.J. BeATy. 1993. Polymerase chain reaction approaches to Culicoides (Diptera: Ceratopogonidae) identification. Journal of 
Medical Entomology, Lanham, 30 (1): 228-232.

Rosa-Freitas, M.G.; R. Lourenço-de-Oliveira; C.J. Carvalho-Pinto; C. Flores-Mendoza \& T.F. Silva-Do-Nascimento. 1998. Anopheline species complexes in Brazil. Current knowledge of those related to malaria transmission. Memórias do Instituto Oswaldo Cruz, Rio de Janeiro, 93 (5): 651-655.

Sallum, M.A.M.; T.R. Schultz \& R.C. Wilkerson. 2000. Phylogeny of Anophelinae (Diptera Culicidae) based on morphological characters. Annals of Entomological Society of America, Lanham, 93 (4): 745-775.

Wilkerson, R.C. \& E.L. Peyton. 1991. The brazilian malaria vector Anopheles (Kerteszia) cruzii: life stages and biology (Diptera: Culicidae). Mosquito Systematics, Washington, 23 (2): 110-122.

Wilkerson, R.C.; T.J. Parsons; T.A. Klein; T.V. Gaffigan; E. Bergo
\& J. Consolim. 1995a. Diagnosis by random amplified DNA polymerase chain reaction of four cryptic species related to Anopheles (Nyssorhynchus) albitarsis (Diptera: Culicidae) from Paraguay, Argentina, and Brazil. Journal of Medical Entomology, Lanham, 32 (5): 697-704.

WilKerson, R.C.; T.V. GafFigan \& J.B. Lima. 1995b. Identification of species related to Anopheles (Nysshorhyncus) albitarsis by random amplified polymorphic DNA-polymerase chain reaction (Diptera: Culicidae). Memórias do Instituto Oswaldo Cruz, Rio de Janeiro, 90 (6): 731-732.

Zavortink, T.J. 1973. Mosquitos studies (Diptera, Culicidae). XXIX. A review of the subgenus Kerteszia of Anopheles. Contributions of American Entomological Institute, Gainesville, 9 (3): 1-59.

Recebido em 07.IV.2005; aceito em 14.XI.2005. 